\title{
Quinolone Resistance Detection by PCR-RFLP and Multiplex-PCR among Extended- Spectrum $\beta$ - Lactamase Producing Enterobacteriaceae
}

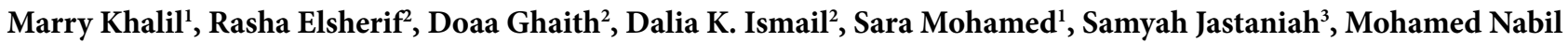 \\ Alama $^{4}$ and Gamal Karrouf ${ }^{5,6^{*}}$ \\ ${ }^{1}$ Botany and Microbiology Department, Faculty of Science, Cairo University \\ ${ }^{2}$ Clinical and Chemical Pathology Department, Faculty of Medicine, Cairo University \\ ${ }^{3}$ Biology Department, Faculty of Science, King Abdulaziz University, Jeddah, Saudi Arabia \\ ${ }^{4}$ Consultant Adult Interventional Cardiologist, King Abdulaziz Hospital, King Abdulaziz University, Jeddah 21589, Saudi Arabia \\ ${ }^{5}$ Faculty of Science, Medical Physics Department, King Abdulaziz University, Jeddah 21589, Saudi Arabia \\ ${ }^{6}$ Surgery, Anaesthesiology and Radiology Department, Faculty of Veterinary Medicine, Mansoura University, Mansoura, 35516 Dakahlia, Egypt
}

\begin{abstract}
Quinolone resistance limits the therapeutic potential for the Extended-Spectrum $\beta$ - lactamase (ESBL) producing Enterobacteriaceae. The aim of this study was to investigate the most common mechanisms of quinolones resistance in ESBL- producing Enterobacteriaceae using both phenotypic and genotypic methods. Out of 1766 clinical isolates collected between October 2012 and September 2013, 219 Enterobacteriaceae clinical isolates were ESBL producers, nalidixic acid and ciprofloxacin resistant were identified by Matrix-Assisted Laser Desorption/Ionization Time-of-Flight Mass Spectrometry (MALDITOF/MS) and the Minimal Inhibitory Concentration (MIC) values of ciprofloxacin and nalidixic acid wasdetected before and after addition of phenylalanine-arginine $\beta$-naphthylamide $(\mathrm{Pa} \beta \mathrm{N})$ efflux pump inhibitor. Thirty three isolates were selected for screening of the plasmid-mediated fluoroquinolone resistance (PMQR) genes; ( $q n r, a a c\left(6^{\prime}\right)-I b-c r$ and $\left.q e p A\right)$ and the efflux pump genes (oqxAB genes) by multiplex PCR. Whereas GyrA and ParC genes mutations were detected by PCR-RFLP assay. The Pa $\beta \mathrm{N}$ changed the MIC values of 28 isolates. The GyrA gene mutation was detected in 24/33 (72.7\%), while the par C gene mutation was detected in 3/33 (9.1\%). Qnr-genes were detected in 13/33 (39.4\%), aac(6')-Ib gene was detected in $24 / 33(72.7 \%)$. qepA gene was detected in only one Klebsiella pneumoniae isolate. Finally the oqxA gene was detected in $16 / 33$ (48.5\%) of the studied isolates. The present study indicated that the $\mathrm{Pa} \beta \mathrm{N}$ was an effective phenotypic screening method for quinolones resistance efflux pump; moreover PCR-RFLP offered simple and rapid method for detection of ciprofloxacin-resistance that could be useful for clinical diagnosis and epidemiological studies
\end{abstract}

\section{Introduction}

Enterobacteriaceae are among the most important etiological factors of nosocomial and community acquired infections. The most commonly isolated pathogens are Klebsiellapneumoniae, Escherichia coli and Enterobacter spp. Salmonella and Shigella spp [1]. The prevalence of Gram-negative microorganisms that are resistant to different antibiotics and the resultant deficit in antibiotics that emphasizes the urgent need for novel therapeutic agents for the treatment of Gram-negative infectious agents [2]. Beta-lactams and fluoroquinolones constitute the main therapeutic agent of choices to treat infections caused by these pathogens. However, the development of resistance to these compounds, especially, by Gram negative microorganisms constitutes a noticeable success of bacterial survival $[3,4,5]$. Quinolones resistance complicates the treatment of infections caused by ESBL-producing Enterobacteriaceae strains [6]. The most important mechanisms involved in quinolones resistance in Enterobacteriaceae are (i) accumulation of chromosomal mutations primarily in the quinolone resistance-determining regions (QRDRs) of the target genes, gyrA which encodes DNA and parC which encodes topoisomerase IV [7]. (ii) Up regulation of the native efflux pumps which decreases the intracellular drug accumulation [8] alone or in addition to decreased expression of outer membrane proteins [9]. Three plasmid-mediated fluoroquinolone resistance (PMQR) mechanisms have been described; including (i) the Qnr (qnrA, qnrB, $q n r S$, $q n r C$ and $q n r D$ proteins, (ii) the $a a c\left(6^{\prime}\right)-I b-c r$ enzyme, and, (iii) QepA and oqxAB plasmid-mediated efflux pumps [5]. ESBLproducing isolates are commonly associated with PMQR genes in
Enterobacteriaceae [6]. Use of efflux pump inhibitors is a unique anti-resistance approach that can return activity for different families of antibiotics. However, their clinical use is difficult due to the toxicity, stability, selectivity and bioavailability of available molecules [10]. Phenylalanine-arginine $\beta$-naphthylamide $(\mathrm{PA} \beta \mathrm{N})$ is a well-studied efflux pump inhibitor (EPI) that is routinely combined with fluoroquinolone antibiotics. As a result of the competition between $\mathrm{P} \beta \mathrm{NA}$ and the antibiotic, $\mathrm{P} \beta \mathrm{NA}$ is extruded outside by the efflux pump and the antibiotic reaches its effective concentration inside the cell [11]. The aim of this study was to investigate the most common mechanisms of quinolones resistance in ESBL-producing Enterobacteriaceae clinical isolates using both phenotypic method by testing the effect of P $\beta$ NA (EPI) and genotypic methods by using multiplex- PCR to detect plasmid mediated (PMQR) and PCR-RFLP assay to detect mutations in the quinolone-resistance determining

"Corresponding Author: Prof. Gamal Karrouf, Faculty of Science, Medical Physics Department, King Abdulaziz University, 21589Jeddah, Saudi Arabia and Surgery, Anesthesiology and Radiology Department, Faculty of Veterinary Medicine, Mansoura University, Mansoura, 35516 Dakahlia, Egypt; E-mail: gkarrouf@kau. edu.sa

Citation: Khalil M, Elsherif R, Ghaith D, Ismail DK, Mohamed S, et al. (2017) Quinolone Resistance Detection by PCR-RFLP and Multiplex-PCR among Extended- Spectrum $\beta$ - Lactamase Producing Enterobacteriaceae. Int J Clin Med Microbiol 2: 119. doi: https://doi.org/10.15344/2456-4028/2017/119

Copyright: (C) 2016 Khalil et al. This is an open-access article distributed under the terms of the Creative Commons Attribution License, which permits unrestricted use, distribution, and reproduction in any medium, provided the original author and source are credited. 
Citation: Khalil M, Elsherif R, Ghaith D, Ismail DK, Mohamed S, et al. (2017) Quinolone Resistance Detection by PCR-RFLP and Multiplex-PCR among Extended- Spectrum $\beta$ - Lactamase Producing Enterobacteriaceae. Int J Clin Med Microbiol 2: 119. doi: https://doi.org/10.15344/2456-4028/2017/119

Page 2 of 9

regions of gyrA and parC. The detection of mutations associated with reduced susceptibility to fluoroquinolones by PCR-RFLP is well thought-out in our country as it serves as a specific, rapid, inexpensive, and simple testing alternative to sequencing assays.

\section{Material and Methods}

\section{Ethics statement}

The present study was approved by the Faculty of Medicine Cairo University Hospital, Egypt. Written informed consent was not necessary for this retrospective study, as it was part of our standard microbiological routine. Patient data were anonymous for the purposes of this analysis, and all confidential patient information was protected in accordance with Egyptian law.

\section{Hospital setting}

The study was conducted at Cairo University Hospital, which serves patients in Cairo (Egypt) and provides medical and surgical care in all medical specialties. The study took place from October 2012 to September 2013. The study conforms to the relevant regulatory standards and is in accordance with the recommendations of the Clinical and Laboratory Standards Institute (CLSI) guidelines.

\section{Clinical isolates (selection and identification)}

Out of 1766 clinical bacterial isolates collected from October 2012 to September 2013, a total of 219 Enterobacteriaceae clinical isolates were ESBL- producers, nalidixic acid and ciprofloxacin resistant. All isolates were collected from inpatients admitted at Kasr Al-Ainy Cairo University Hospital, Egypt. All 219 isolates were processed and identified by the standard procedures of the Clinical and Laboratory Standards Institute guidelines [12] and were identified to the species level using MALDI-TOF/MS with score values > (1.9) using the Bruker software microflex RTC version 3.1 and then stored in brain heart infusion broth with $15 \%$ glycerol at $-60^{\circ} \mathrm{C}$ until further analysis.

\section{Phenotypic detection of Quinolones resistance}

All 219 Enterobacteriaceae isolates were subjected to phenotypic detection of quinolones resistance.

\section{Antimicrobial susceptibility testing}

Antimicrobial susceptibility testing was performed by the disc diffusion method (Modified Kirby-Bauer technique) using Muller Hinton agar, aerobic incubation at $35 \mathrm{oC}$ for $16-18 \mathrm{~h}$. Antimicrobial discs, Imipenem (10 mcg), Meropenem (10 mcg), Gentamicin (10 $\mathrm{mcg}$ ), Ciprofloxacin $(5 \mathrm{mcg})$, Amikacin $(30 \mathrm{mcg})$, Cotrimoxazole $(25 \mathrm{mcg})$, Cefepime $(30 \mathrm{mcg})$, Cefotaxime $(30 \mathrm{mcg})$, Cefotaxime+ Clavulanic acid $(30 / 10 \mathrm{mcg})$, Aztreonam $(30 \mathrm{mcg})$, Ceftazidime (30 $\mathrm{mcg})$, Ceftazidime + Clavulanic acid $(30 / 10 \mathrm{mcg})$, AmoxacillinClavulanic acid $(20 / 10 \mathrm{mcg})$, and Cefoxitin $(30 \mathrm{mcg})$ were obtained from Oxoid Co. (Oxoid Limited, Basingstoke, Hampshire, England). Phenotypic screening and confirmation of Extended-Spectrum $\beta$-LactamaseExtended-Spectrum $\beta$-LactamaseESBL production was done using the combined disc tests [12].

\section{Minimal Inhibitory Concentration}

Minimal inhibitory concentration of nalidixic acid (NA) and ciprofloxacin (CIP) was determined by broth microdilution method following CLSI guidelines 2012. CIP and NA MICs were measured in microdilution plates with a final volume of $200 \mu \mathrm{l} /$ well. $100 \mu \mathrm{l}$ Mueller-Hinton broth was added in each well plus an extra $74.4 \mu \mathrm{l}$ only in the first well and $25.6 \mu \mathrm{l}$ ciprofloxacin from a $2 \mathrm{mg} / \mathrm{ml}$ stock solution. Serial dilutions were done and $100 \mu \mathrm{l}$ of bacterial inoculum with $105 \mathrm{CFU} / \mathrm{ml}$ was added in each well, obtaining ciprofloxacin concentration of $128 \mu \mathrm{g} / \mathrm{ml}$ in the first well and $0.06 \mu \mathrm{g} / \mathrm{ml}$ in the last one. In case of Nalidixic acid $10.24 \mu \mathrm{l}$ was added in the first well from a $5 \mathrm{mg} / \mathrm{ml}$ stock solution. After serial dilutions and addition of bacterial inoculum with $105 \mathrm{CFU} / \mathrm{ml}$ in each well; Nalidixic acid concentrations of $128 \mu \mathrm{g} / \mathrm{ml}$ in the first and $0.06 \mu \mathrm{g} / \mathrm{ml}$ in the last wells were obtained. The lowest antibiotic concentration that inhibits the growth was considered as the MIC value.

\section{Phenylalanine-arginine $\beta$-naphthylamide (PaßN) efflux pump inhibitor}

According to the CLSI (2010) recommendations, before and after addition of P $\beta N A$ (Sigma-Aldrich Co, St Louis, MO, USA) the lowest antibiotic concentration that inhibits the growth was considered as the MIC value. One hundred $\mu \mathrm{L}$ of Mueller-Hinton broth containing the bacterial suspensions was added to the wells of a sterile microdilution plate. By adding $50 \mu \mathrm{L}$ of suitable concentrations of CIP and NA to the first line of wells, serial dilutions were performed. $20 \mu \mathrm{L}$ constant P $\beta$ NA concentration solution was added $(20 \mu \mathrm{g} / \mathrm{ml})$ to each well. At least four fold decreases in the MIC values of ciprofloxacin and nalidixic acid was evaluated as the presence of the efflux pump [13].

\section{Genotypic detection of Quinolones resistance}

Out of a total of 219 isolates, 28 isolates showed MIC changes after addition of $\mathrm{P} \beta \mathrm{NA}, 5$ isolates were added as a negative control. A total of 33 isolates were subjected to PCR assay of the PMQR genes, as well as PCR amplification of the QRDRs of gyrA and parC, followed by RFLP to detect mutations in $g y r A$ and parC.

\section{DNA extraction}

Extraction of DNA was performed using the QIAmp DNA mini kit (50) (QIAGEN GmbH, Hilden, Germany Cat. No.51304) according to manufacturer instructions.

\section{PCR amplification}

PCR amplifications of the quinolone resistance determining regions (QRDRs) of gyrA and parC were carried out using the primers listed in Table 1 . The primer used to amplify a 344-bp fragment containing the QRDR of the gyrA gene. The conditions were $94^{\circ} \mathrm{C}$ for $60 \mathrm{sec}, 55^{\circ} \mathrm{C}$ for $45 \mathrm{sec}$, and $72^{\circ} \mathrm{C}$ for $60 \mathrm{sec}$ for 30 cycles. For $\operatorname{ParC}$ gene, amplification was carried out for $35 \mathrm{cycles}$ at $94^{\circ} \mathrm{C}$ for $30 \mathrm{sec}, 55^{\circ} \mathrm{C}$ for $30 \mathrm{sec}$, and $72{ }^{\circ} \mathrm{C}$ for $30 \mathrm{sec}$ to amplify a $168 \mathrm{bp}$ fragment [14]. PCR products were submitted to electrophoresis on a1.5\% agarose gel containing ethidium bromide to visualize the amplified bands under UV.

\section{Restriction Fragment Length Polymorphism (RFLP)}

All PCR products positive for $g y r A$ and parC genes were further analyzed by digestion with Hinf I (Thermo scientific FastDigest restriction enzyme, Fermentas-Lithuania) to identify mutations [15]. The wild-type $g y r A$ contains the artificial Hinf I cleavage site. Consequently, Hinf I digests the amplified 344-bp products to produce two fragments for gyrA 210 and 272 bp respectively, and also for the wild type parC Hinfl digest 168 PCR product for 32 and $65 \mathrm{bp}$ respectively. Ten $\mu \mathrm{L}$ of each amplification product was mixed 
Citation: Khalil M, Elsherif R, Ghaith D, Ismail DK, Mohamed S, et al. (2017) Quinolone Resistance Detection by PCR-RFLP and Multiplex-PCR among Extended- Spectrum $\beta$ - Lactamase Producing Enterobacteriaceae. Int J Clin Med Microbiol 2: 119. doi: https://doi.org/10.15344/2456-4028/2017/119

Page 3 of 9

\begin{tabular}{|c|c|c|}
\hline No. & gene & sequence \\
\hline \multirow[t]{2}{*}{1} & $q n r A$ Fwd & 5-ATT TCT CAC GCC AGG ATT TG-3 \\
\hline & qnrA Rev & 5-GAT CGG CAA AGG TTA GGT CA-3 \\
\hline \multirow[t]{2}{*}{2} & $q n r B$ Fwd & 5-GAT CGT GAA AGC CAG AAA GG-3 \\
\hline & $q n r B \operatorname{Rev}$ & 5-ACG ATG CCT GGT AGT TGT CC-3 \\
\hline \multirow[t]{2}{*}{3} & $q n r S$ Fwd & 5-ACG ACA TTC GTC AAC TGC AA-3 \\
\hline & qnrS Rev & 5-TAA ATT GGC ACC CTG TAG GC-3 \\
\hline \multirow[t]{2}{*}{4} & $a a c\left(6^{\prime}\right)-I b F w d$ & 5-TTG CGA TGC TCT ATG AGT GGC TA-3 \\
\hline & $a a c\left(6^{\prime}\right)-I b \operatorname{Rev}$ & 5-CTC GAA TGC CTG GCG TGT TT-3 \\
\hline \multirow[t]{2}{*}{5} & qepA Fwd & 5-GCA GGT CCA GCA GCG GGT AG-3 \\
\hline & qepA Rev & 5-CTT CCT GCC CGA GTA TCG TG-3 \\
\hline \multirow[t]{2}{*}{6} & oqxA Fwd & 5-CTC GGC GCG ATG ATG CT-3 \\
\hline & oqxA Rev & 5-CCA CTC TTC ACG GGA GAC GA-3 \\
\hline \multirow[t]{2}{*}{7} & oqxB Fwd & 5- TTC TCC CCC GGC GGG AAG TAC-3 \\
\hline & $o q x B \operatorname{Rev}$ & 5- CTC GGC CAT TTT GGC GCG TA-3 \\
\hline \multirow[t]{2}{*}{8} & gyrAWF & 5-AAA TCT GCC CGT GTC GTT GGT-3 \\
\hline & gyrAWR & 5-GCC ATA CCT ACG GCG ATA CC-3 \\
\hline \multirow[t]{2}{*}{9} & parCWF & 5-CTG AAT GCC AGC GCC AAA TT-3 \\
\hline & parCWR & 5-GCG AAC GAT TTC GGA TCG TC-3 \\
\hline
\end{tabular}

Table 1 : Primers used in the study.

with $1 \mu \mathrm{L}$ of Hinf I, $2 \mu \mathrm{L}$ of $10 \mathrm{X}$ fast Digest green buffers and 17 $\mu \mathrm{L}$ of water and incubated at $37 \mathrm{C}$ for $5 \mathrm{~min}$. Ten micro-liters of the digested fragments were run in $3 \%$ agarose gel. The gel was stained with ethidium bromide and the DNA bands were visualized with UV transilluminator. DNA ladder (50 pb and $25 \mathrm{bp}$ ) (Promega1) was used as a molecular weight marker.

\section{Detection of Plasmid Mediated Quinolones Resistance Determinants (PMQR)}

Screening of the five PMQR determinants was carried out by two sets of multiplex PCR amplification, one for $q n r A$, qnrB, and $q n r S$ and the other for $a a c\left(6^{\prime}\right)-I b$ and $q e p A$ [14].Also Detection of oqx $A B$ was performed as described elsewhere[16].

\section{Statistical analysis}

The resulting data was analyzed using SSPS version 13 program. Nominal data was expressed as frequency and percentage and compared using Chi square test. The Pvalue $<0.01$ was considered significant.

\section{Results}

Out of 1766 clinical Enterobacteriaceae isolates, 219 (12.4\%) isolates were ESBL producers and quinolone resistant, including; Escherichia coli 98 (44.7\%), Klebsiella pneumoniae 92 (42\%), Salmonella enterica 8 isolates plus one isolate Salmonella enteritidis, one isolate Salmonella choleraesuis and one isolate Salmonella bongori total 11 (5\%), one isolate Enterobacter ludwigii plus two isolates Enterobacter. cloacae total 3 (1.4\%), Proteus mirabilis 8 (3.65\%) and Shigella flexneri 2 $(0.9 \%)$. The most common site of isolation was the urine specimens $112(51.1 \%)$ (The $\mathrm{P}$-value was significant $\mathrm{P}<0.01$ ), wound specimens 65 (29.6\%), sputum specimens 16 (7.3\%) followed by stool specimens
13 (5.9\%). The distribution of clinical isolates according to the clinical specimens are shown in Table 2. The presence of co-resistance among different classes of antibiotic families was significant (The P-value is 0.000346 ) except for carbapenems and polymyxin classes. In our study minimum inhibitory concentrations (MICs) of ciprofloxacin antibiotic and nalidixic acid before and after addition of efflux pump inhibitor $\mathrm{Pa} \beta \mathrm{N}$ resulted in reduction of MIC in total 28 isolates. In E. coli isolates adding $\mathrm{Pa} \beta \mathrm{N}$ resulted in reduction in MIC by more than $2 \log 2$ dilution in 9 samples for ciprofloxacin antibiotic and in 4 samples for nalidixic acid (The P-value is 0.145483 , the result is not significant at $\mathrm{P}<0.10$ ). While addition of $\mathrm{Pa} \mathrm{N}$ to Klebsiella pneumoniae isolates resulted in reduction of MIC by more than $2 \log 2$ dilution in 8 isolates for ciprofloxacin antibiotic and in 5 isolates for nalidixic acid (P-Value is 0.997521, the result is not significant at $\mathrm{P}$ $<0.10)$. Moreover addition of $\mathrm{Pa} \beta \mathrm{N}$ to the Enterobacter $\operatorname{spp}$ isolates resulted in reduction of MIC by more than $2 \log 2$ dilution in 2 samples for both ciprofloxacin and nalidixic acid antibiotic (P-value is 1 , the result was not significant at $\mathrm{P}<0.10$ ). Whereas addition of $\mathrm{Pa} \beta \mathrm{N}$ to the Proteus mirabilis isolates resulted in a reduction of MIC by more than $2 \log 2$ dilution in 2 samples for ciprofloxacin and in 2 samples for nalidixic acid antibiotic, the result is also insignificant at $\mathrm{P}$ $<0.10$. Also addition of $\mathrm{Pa} \beta \mathrm{N}$ to the Salmonella spp isolates resulted in reduction of MIC by more than $2 \log 2$ dilution in 6 samples for both ciprofloxacin and nalidixic acid antibiotic by a percent $100 \%$ ( The result is not significant at $\mathrm{P}<0.10$ ). Finally addition of $\mathrm{Pa} \beta \mathrm{N}$ to the Shigella flexneri isolates resulted in reduction of MIC by more than $2 \log 2$ dilution in the 1 samples for both ciprofloxacin and nalidixic acid antibiotic by a percent $100 \%$ (The P-value is 0.252656 , The result is not significant at $\mathrm{P}<0.10$ ). Thirty three isolates ( 28 of them showed MIC changes after addition of $\mathrm{P} \beta \mathrm{NA}$ in addition to 5 isolates added as a negative control) were selected for further PCR work up, including PMQR genes, as well as PCR amplification of the QRDRs of gyrA and parC, followed by RFLP to detect mutations in $g y r A$ and parC. By PCR-RFLP assay gyrA gene mutation was detected in $24 / 33$ (72.7\%), while par C gene mutation was detected in $3 / 33$ (9.1\%).

The prevalence of $85.7 \%$ of $P M Q R$ genes and qnr-genes were identified in 13/33 (39.3\%) of the clinical isolates as shown in (Figure 1 ), one isolate contained $q n r A$ gene only, one isolate contained the qnrB gene only, one isolate contained both $q n r A$ and $q n r S$ genes and two isolates contained both $q n r B$ and $q n r S$ genes. $\operatorname{Aac}\left(6^{\prime}\right)$-Ib gene was detected in $72.7 \%(24 / 33)$ of the clinical isolates as shown in (Figure 2). The prevalence of aac(6')-Ib-cr was $72.7 \%(8 / 11)$ among E. coli, $88.8 \%(8 / 9)$ among Klebsiella pneumoniae, $66.6 \%(2 / 3)$ among Enterobacter spp., $66.6 \%(2 / 3)$ among Proteus mirabilis and $66.6 \%$ $(4 / 6)$ among salmonella spp clinical isolates. oqxA gene was detected in $51.5 \%(16 / 33)$ of the clinical isolates. The prevalence was $18.1 \%$ (2/11) among E. coli, 66.6\% (2/3) among Enterobacter spp., 33.3\% (1/3) among Proteus mirabilis and 50\% (3/6) among Salmonella spp. Klebsiella pneumoniae isolates showed positive results for oqxA gene by $100 \%(8 / 9)$. Whereas oqxB gene was detected in $21.2 \%(7 / 33)$ of the clinical isolates. QepA gene was detected in only one Klebsiella pneumoniae isolate which was highly resistant to both antibiotics before and after the addition of $\mathrm{Pa} \beta \mathrm{N}$ as shown in (Figure 3).

All E. coli, Enterobacter, Proteus and Salmonella isolates showed negative results for the OqxB gene. Isolates of positive PCR results for efflux pump genes oqxAB showed MIC changes after addition of efflux pump inhibitor $\mathrm{Pa} \beta \mathrm{N}$ in $88.2 \%$ (15/17) for ciprofloxacin and $70.5 \%(12 / 17)$ for nalidixic acid. The results of multiplex-PCR and PCR-RFLP for the tested Enterobacteriaceae clinical isolates are presented in Table 3. 
Citation: Khalil M, Elsherif R, Ghaith D, Ismail DK, Mohamed S, et al. (2017) Quinolone Resistance Detection by PCR-RFLP and Multiplex-PCR among Extended- Spectrum $\beta$ - Lactamase Producing Enterobacteriaceae. Int J Clin Med Microbiol 2: 119. doi: https://doi.org/10.15344/2456-4028/2017/119

Page 4 of 9

\begin{tabular}{|c|c|c|c|c|c|c|c|c|c|}
\hline & $\begin{array}{l}\text { Ciprofloxacin } \\
(\mathrm{mg} / \mathrm{ml})\end{array}$ & $\begin{array}{l}\text { Nalidixic acid } \\
(\mathrm{mg} / \mathrm{ml})\end{array}$ & & $\begin{array}{l}\text { Ciprofloxacin } \\
(\mathrm{mg} / \mathrm{ml})\end{array}$ & $\begin{array}{l}\text { Nalidixic acid } \\
(\mathrm{mg} / \mathrm{ml})\end{array}$ & & & & \\
\hline Isolate & ${ }_{-} \mathrm{P} \beta \mathrm{NA}$ & $+\mathrm{P} \beta \mathrm{NA}$ & ${ }_{-} \mathrm{P} \beta \mathrm{NA}$ & $+\mathrm{P} \beta \mathrm{NA}$ & Isolate & ${ }_{-} \mathrm{P} \beta \mathrm{NA}$ & $+\mathrm{P} \beta \mathrm{NA}$ & ${ }_{-} \mathrm{P} \beta \mathrm{NA}$ & $+\mathrm{P} \beta \mathrm{NA}$ \\
\hline E1 & $>146.66$ & $>146.66$ & $>146.66$ & $>146.66$ & E45 & $>146.66$ & $>146.66$ & $>146.66$ & $>146.66$ \\
\hline E2 & $>146.66$ & $>146.66$ & $>146.66$ & $>146.66$ & E46 & $>146.66$ & $>146.66$ & $>146.66$ & $>146.66$ \\
\hline E3* & 73.33 & $<2.291$ & $>146.66$ & $>146.66$ & $\mathrm{E} 47$ & $>146.66$ & $>146.66$ & $>146.66$ & $>146.66$ \\
\hline $\mathrm{E} 4$ & $>146.66$ & $>146.66$ & $>146.66$ & $>146.66$ & E48 & $>146.66$ & $>146.66$ & $>146.66$ & $>146.66$ \\
\hline E5 & $<2.291$ & $<2.291$ & $>146.66$ & $>146.66$ & E49 & $>146.66$ & 73.33 & $>146.66$ & 146.66 \\
\hline E6 & $>146.66$ & $>146.66$ & $>146.66$ & $>146.66$ & E50 & $>146.66$ & $<2.291$ & $>146.66$ & $>146.66$ \\
\hline E7 & $>146.66$ & $>146.66$ & $>146.66$ & $>146.66$ & E51 & $>146.66$ & $>146.66$ & $>146.66$ & $>146.66$ \\
\hline E8 & $>146.66$ & $>146.66$ & $>146.66$ & $>146.66$ & E52 & $>146.66$ & $<2.291$ & $>146.66$ & $<2.291$ \\
\hline E9 & 73.33 & 73.33 & $>146.66$ & $>146.66$ & E53 & $>146.66$ & $>146.66$ & $>146.66$ & $>146.66$ \\
\hline E11* & $>146.66$ & 146.66 & $>146.66$ & $>146.66$ & E55 & 146.66 & 146.66 & $>146.66$ & $>146.66$ \\
\hline E12 & 73.33 & 73.33 & $>146.66$ & $>146.66$ & E56 & $>146.66$ & $>146.66$ & $>146.66$ & $>146.66$ \\
\hline E13 & $>146.66$ & $>146.66$ & $>146.66$ & $>146.66$ & E57 & 146.66 & 146.66 & $>146.66$ & $>146.66$ \\
\hline E14 & $>146.66$ & $>146.66$ & $>146.66$ & $>146.66$ & E58 & $>146.66$ & $>146.66$ & $>146.66$ & $>146.66$ \\
\hline E15 & $>146.66$ & $>146.66$ & $>146.66$ & $>146.66$ & $\mathrm{E} 59^{*}$ & 73.33 & 73.33 & $>146.66$ & $>146.66$ \\
\hline E16 & 73.33 & 73.33 & $>146.66$ & $>146.66$ & E60 & $>146.66$ & $>146.66$ & $>146.66$ & $>146.66$ \\
\hline E17 & $>146.66$ & $<2.291$ & $>146.66$ & $<2.291$ & E61 & $>146.66$ & $>146.66$ & $>146.66$ & $>146.66$ \\
\hline E18 & $>146.66$ & $>146.66$ & $>146.66$ & $>146.66$ & E62 & $>146.66$ & $>146.66$ & $>146.66$ & $>146.66$ \\
\hline E19 & $>146.66$ & $>146.66$ & $>146.66$ & $>146.66$ & E63 & 73.33 & 73.33 & $>146.66$ & $>146.66$ \\
\hline E20* & $>146.66$ & $>146.66$ & $>146.66$ & $>146.66$ & E64 & $>146.66$ & $>146.66$ & $>146.66$ & $>146.66$ \\
\hline E21 & $>146.66$ & $>146.66$ & $>146.66$ & $>146.66$ & E65 & $>146.66$ & $>146.66$ & $>146.66$ & $>146.66$ \\
\hline E23 & $>146.66$ & $>146.66$ & $>146.66$ & $>146.66$ & E67 & $>146.66$ & $>146.66$ & $>146.66$ & $>146.66$ \\
\hline E24 & $>146.66$ & $>146.66$ & $>146.66$ & $>146.66$ & E68 & $>146.66$ & $>146.66$ & $>146.66$ & $>146.66$ \\
\hline E25 & $>146.66$ & $>146.66$ & $>146.66$ & $>146.66$ & E69 & $>146.66$ & $>146.66$ & $>146.66$ & $>146.66$ \\
\hline E26* & $>146.66$ & 9.1663 & $>146.66$ & $>146.66$ & E70 & $>146.66$ & $>146.66$ & $>146.66$ & $>146.66$ \\
\hline E27 & $>146.66$ & $>146.66$ & $>146.66$ & $>146.66$ & E71 & $>146.66$ & $>146.66$ & $>146.66$ & $>146.66$ \\
\hline E28 & $>146.66$ & $>146.66$ & $>146.66$ & $>146.66$ & E72 & $>146.66$ & $>146.66$ & $>146.66$ & $>146.66$ \\
\hline E29 & $>146.66$ & $>146.66$ & $>146.66$ & $>146.66$ & E73 & $>146.66$ & $>146.66$ & $>146.66$ & $>146.66$ \\
\hline E30 & $<2.291$ & $<2.291$ & $>146.66$ & $>146.66$ & E74 & $>146.66$ & $>146.66$ & $>146.66$ & $>146.66$ \\
\hline E31 & $>146.66$ & $>146.66$ & $>146.66$ & $>146.66$ & E75 & 73.33 & 73.33 & $>146.66$ & $>146.66$ \\
\hline E32 & $>146.66$ & $>146.66$ & $>146.66$ & $>146.66$ & E76 & 146.66 & 146.66 & $>146.66$ & $>146.66$ \\
\hline E33 & $>146.66$ & $>146.66$ & $>146.66$ & $>146.66$ & E77* & $>146.66$ & 9.1663 & $>146.66$ & 36.665 \\
\hline E34 & $>146.66$ & $>146.66$ & $>146.66$ & $>146.66$ & E78* & $>146.66$ & 36.665 & $>146.66$ & 146.66 \\
\hline E35 & $>146.66$ & $>146.66$ & $>146.66$ & $>146.66$ & E79 & $>146.66$ & $>146.66$ & $>146.66$ & $>146.66$ \\
\hline E36 & $>146.66$ & $>146.66$ & $>146.66$ & $>146.66$ & E80 & $>146.66$ & $>146.66$ & $>146.66$ & $>146.66$ \\
\hline E37 & $>146.66$ & $>146.66$ & $>146.66$ & $>146.66$ & E81 & $>146.66$ & $>146.66$ & $>146.66$ & $>146.66$ \\
\hline E38 & $>146.66$ & $>146.66$ & $>146.66$ & $>146.66$ & E82* & $>146.66$ & 36.665 & $>146.66$ & $>146.66$ \\
\hline E39 & 146.66 & 146.66 & $>146.66$ & $>146.66$ & E83 & $>146.66$ & $>146.66$ & $>146.66$ & $>146.66$ \\
\hline E40 & $>146.66$ & $>146.66$ & $>146.66$ & $>146.66$ & E84 & $>146.66$ & $>146.66$ & $>146.66$ & $>146.66$ \\
\hline E41 & $>146.66$ & $>146.66$ & $>146.66$ & $>146.66$ & E85 & $>146.66$ & $>146.66$ & $>146.66$ & $>146.66$ \\
\hline $\mathrm{E} 42$ & $>146.66$ & $>146.66$ & $>146.66$ & $>146.66$ & E86* & $>146.66$ & $>146.66$ & $>146.66$ & $>146.66$ \\
\hline $\mathrm{E} 43$ & $>146.66$ & $>146.66$ & $>146.66$ & $>146.66$ & E87 & $>146.66$ & $>146.66$ & $>146.66$ & $>146.66$ \\
\hline E44 & $>146.66$ & $>146.66$ & $>146.66$ & $>146.66$ & E88 & $>146.66$ & $>146.66$ & $>146.66$ & $>146.66$ \\
\hline
\end{tabular}

Table (2): MIC changes of ciprofloxacin and nalidixic acid before and after addition of PA $\beta \mathrm{N}$ for 98 E.coli. isolates. 
Citation: Khalil M, Elsherif R, Ghaith D, Ismail DK, Mohamed S, et al. (2017) Quinolone Resistance Detection by PCR-RFLP and Multiplex-PCR among Extended- Spectrum $\beta$ - Lactamase Producing Enterobacteriaceae. Int J Clin Med Microbiol 2: 119. doi: https://doi.org/10.15344/2456-4028/2017/119

Page 5 of 9

\begin{tabular}{|c|c|c|c|c|c|c|c|c|c|}
\hline & Ciprofloxacin $(\mathrm{mg} / \mathrm{ml})$ & Nalidixic acid $(\mathrm{mg} / \mathrm{ml})$ & & Ciprofloxacin (mg/ml) & Nalidixic acid $(\mathrm{mg} / \mathrm{ml})$ & & & & \\
\hline Isolate & - $\mathrm{P} \beta \mathrm{NA}$ & $+\mathrm{P} \beta \mathrm{NA}$ & _P $\mathrm{P} \beta \mathrm{NA}$ & $+\mathrm{P} \beta \mathrm{NA}$ & Isolate & ${ }_{-} \mathrm{P} \beta \mathrm{NA}$ & $+\mathrm{P} \beta \mathrm{NA}$ & ${ }_{-} \mathrm{P} \beta \mathrm{NA}$ & $+\mathrm{P} \beta \mathrm{NA}$ \\
\hline K1 & 75 & 2.3438 & $>75$ & $>75$ & $\mathrm{~K} 47^{*}$ & $>75$ & 2.3438 & $>75$ & 37.5 \\
\hline K2 & 18.75 & $<1.17$ & $>75$ & $<1.17$ & K48 & $>75$ & $>75$ & $>75$ & $>75$ \\
\hline $\mathrm{K}^{*}$ & $>75$ & 2.3438 & $>75$ & 9.375 & K49 & $>75$ & $>75$ & $>75$ & $>75$ \\
\hline K4 & 9.375 & $<1.17$ & 37.5 & 37.5 & $\mathrm{~K} 50^{*}$ & $>75$ & $>75$ & $>75$ & $>75$ \\
\hline K5 & 9.375 & $<1.17$ & 37.5 & 37.5 & K51 & $>75$ & $>75$ & $>75$ & $>75$ \\
\hline K6 & 9.375 & 9.375 & 37.5 & 37.5 & K52 & $>75$ & $>75$ & $>75$ & $>75$ \\
\hline K7 & 2.3438 & $<1.17$ & $>75$ & $<1.17$ & K53 & 4.6875 & 4.6875 & 37.5 & 37.5 \\
\hline K8 & $>75$ & $>75$ & $>75$ & $>75$ & K54 & 75 & 75 & $>75$ & $>75$ \\
\hline K9 & $>75$ & 9.375 & $>75$ & $>75$ & K55 & $>75$ & $>75$ & $>75$ & $>75$ \\
\hline K10 & $>75$ & $>75$ & $>75$ & $>75$ & K56 & $>75$ & $>75$ & $>75$ & $>75$ \\
\hline K11 & 37.5 & $<1.17$ & $>75$ & $<1.17$ & K57 & 75 & 75 & $>75$ & $>75$ \\
\hline K12 & $>75$ & $>75$ & $>75$ & $>75$ & K58 & 4.6875 & 4.6875 & $>75$ & $>75$ \\
\hline K13 & $>75$ & 9.375 & $>75$ & $>75$ & K59 & 75 & 75 & $>75$ & $>75$ \\
\hline K14 & $>75$ & $>75$ & $>75$ & $>75$ & K60 & 18.75 & 18.75 & $>75$ & $>75$ \\
\hline K15 & $>75$ & $>75$ & $>75$ & $>75$ & K61 & 75 & 37.5 & $>75$ & 75 \\
\hline K16 & 9.375 & 9.375 & 37.5 & 37.5 & K62* & $>75$ & 18.75 & $>75$ & 75 \\
\hline K17* & $>75$ & $>75$ & $>75$ & $>75$ & K63 & 75 & 75 & $>75$ & $>75$ \\
\hline K18 & 75 & 75 & $>75$ & $>75$ & K64 & $>75$ & $>75$ & $>75$ & $>75$ \\
\hline K19* & $>75$ & 18.75 & $>75$ & 18.75 & K65 & $>75$ & $>75$ & $>75$ & $>75$ \\
\hline K20 & $>75$ & $>75$ & $>75$ & $>75$ & K66 & $>75$ & $>75$ & $>75$ & $>75$ \\
\hline K21 & $>75$ & $>75$ & $>75$ & $>75$ & K67 & $>75$ & $>75$ & $>75$ & $>75$ \\
\hline $\mathrm{K} 22$ & $>75$ & $>75$ & $>75$ & $>75$ & K68 & $>75$ & $>75$ & $>75$ & $>75$ \\
\hline $\mathrm{K} 23$ & $>75$ & $>75$ & $>75$ & $>75$ & K69 & $>75$ & $>75$ & $>75$ & $>75$ \\
\hline $\mathrm{K} 24$ & $>75$ & $>75$ & $>75$ & $>75$ & K70 & $>75$ & $>75$ & $>75$ & $>75$ \\
\hline K25 & $>75$ & $>75$ & $>75$ & $>75$ & K71* & 75 & 37.5 & $>75$ & $<1.1718$ \\
\hline $\mathrm{K} 26^{*}$ & $>75$ & 75 & $>75$ & $>75$ & K72 & 2.3438 & 2.3438 & 4.6875 & 4.6875 \\
\hline K27 & $>75$ & $>75$ & $>75$ & $>75$ & K73 & $>75$ & $>75$ & $>75$ & $>75$ \\
\hline K28 & $>75$ & $>75$ & $>75$ & $>75$ & K74 & $>75$ & $>75$ & $>75$ & $>75$ \\
\hline K29 & $>75$ & $>75$ & $>75$ & $>75$ & K75 & 75 & 75 & $>75$ & $>75$ \\
\hline K30 & $>75$ & $>75$ & $>75$ & $>75$ & K76 & 9.375 & 9.375 & $>75$ & $>75$ \\
\hline $\mathrm{K} 31$ & $>75$ & $>75$ & $>75$ & $>75$ & K77 & $>75$ & $>75$ & $>75$ & $>75$ \\
\hline K32 & $>75$ & $>75$ & $>75$ & $>75$ & K78 & $>75$ & $>75$ & $>75$ & $>75$ \\
\hline $\mathrm{K} 33^{*}$ & $>75$ & 9.375 & $>75$ & $>75$ & K79 & $>75$ & $>75$ & $>75$ & $>75$ \\
\hline K34 & $>75$ & 75 & $>75$ & $>75$ & K80 & $>75$ & $>75$ & $>75$ & $>75$ \\
\hline K35 & $>75$ & $>75$ & $>75$ & $>75$ & K81 & $>75$ & $>75$ & $>75$ & $>75$ \\
\hline K36 & $>75$ & $>75$ & $>75$ & $>75$ & K82 & $>75$ & $>75$ & $>75$ & $>75$ \\
\hline K37 & $>75$ & $>75$ & $>75$ & $>75$ & K83 & $>75$ & $>75$ & $>75$ & $>75$ \\
\hline K38 & 4.6875 & 4.6875 & $>75$ & $>75$ & K84 & $>75$ & $>75$ & $>75$ & $>75$ \\
\hline K39 & 75 & 75 & $>75$ & $>75$ & K85 & 9.375 & 9.375 & $>75$ & $>75$ \\
\hline K40 & $<1.17$ & $<1.17$ & $<1.17$ & $<1.17$ & K86 & $>75$ & $>75$ & $>75$ & $>75$ \\
\hline K41 & $>75$ & $>75$ & $>75$ & $>75$ & K87 & $>75$ & $>75$ & $>75$ & $>75$ \\
\hline K42 & $>75$ & $>75$ & $>75$ & $>75$ & K88 & $>75$ & $>75$ & $>75$ & $>75$ \\
\hline K43 & 18.75 & $<1.17$ & $>75$ & $<1.17$ & K89 & $>75$ & $>75$ & $>75$ & $>75$ \\
\hline K44 & $>75$ & $>75$ & $>75$ & $>75$ & K90 & $>75$ & $>75$ & $>75$ & $>75$ \\
\hline K45 & $<1.1718$ & $<1.1718$ & $<1.1718$ & $<1.1718$ & K91 & $>75$ & $>75$ & $>75$ & $>75$ \\
\hline K46 & $>75$ & $>75$ & $>75$ & $>75$ & K92 & 75 & 75 & $>75$ & $>75$ \\
\hline
\end{tabular}

Table : MIC changes of ciprofloxacin and nalidixic acid before and after addition of PA $\beta \mathrm{N}$ for 92 Klebsiella spp. isolates. 
Citation: Khalil M, Elsherif R, Ghaith D, Ismail DK, Mohamed S, et al. (2017) Quinolone Resistance Detection by PCR-RFLP and Multiplex-PCR among Extended- Spectrum $\beta$ - Lactamase Producing Enterobacteriaceae. Int J Clin Med Microbiol 2: 119. doi: https://doi.org/10.15344/2456-4028/2017/119

Page 6 of 9

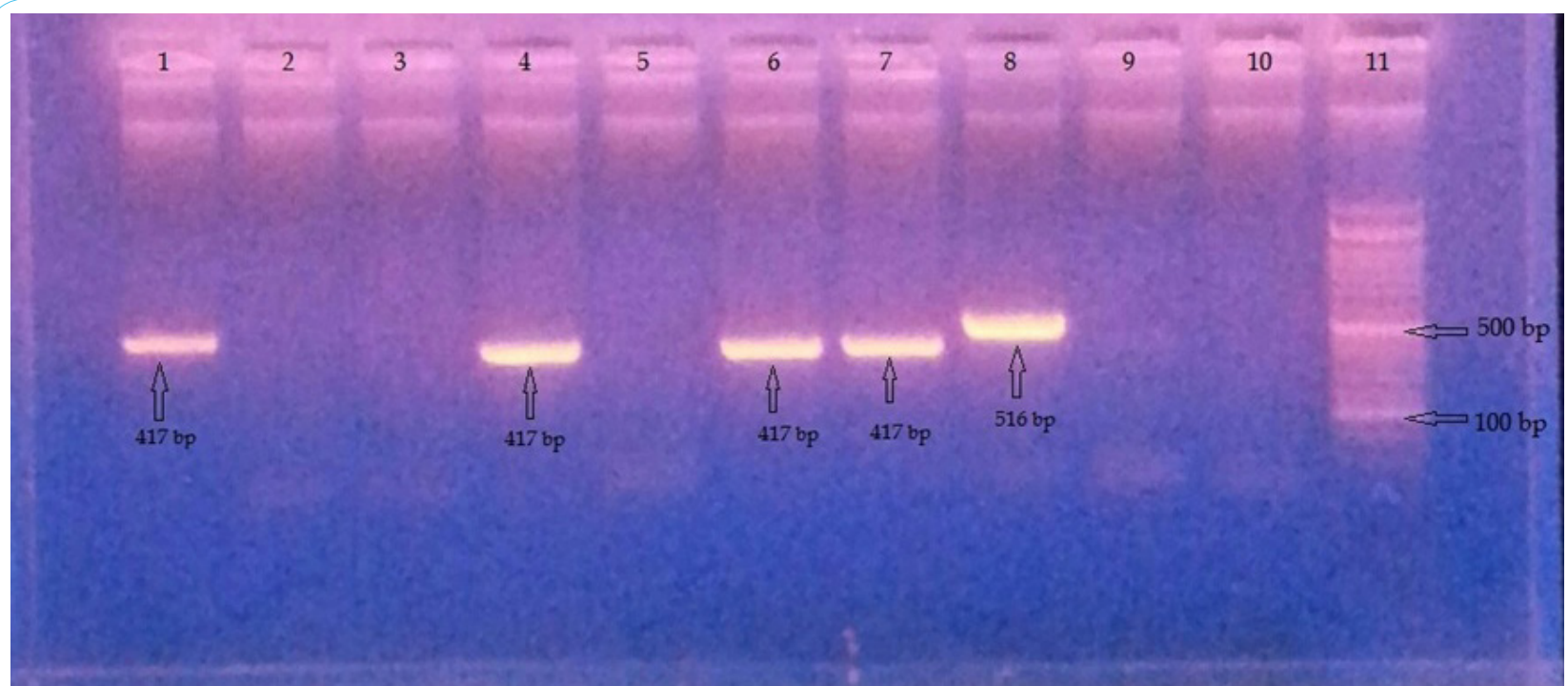

Figure 1: Shows agarose gel electrophoresis of multiplex PCR of $q n r A, q n r B$ and $q n r S$ genes. Lane 1-10: represent the clinical isolates expression of qnrA gene at 516 bp., qnrB gene at $469 \mathrm{bp}$ and qnrS at 417 bp, Lane 11 represent marker.



Figure 2: Shows agarose gel electrophoresis of the PCR. Lane 1-10: represent the clinical isolates expression of Aac(6')-Ib gene at 482 bp., Lane 11 represent marker.



Figure 3: Shows agarose gel electrophoresis of the PCR. Lane 1-10: represent the clinical isolates expression of qepA gene at 199 bp., Lane 11 represent marker. 
Citation: Khalil M, Elsherif R, Ghaith D, Ismail DK, Mohamed S, et al. (2017) Quinolone Resistance Detection by PCR-RFLP and Multiplex-PCR among Extended- Spectrum $\beta$ - Lactamase Producing Enterobacteriaceae. Int J Clin Med Microbiol 2: 119. doi: https://doi.org/10.15344/2456-4028/2017/119

Page 7 of 9

\begin{tabular}{|c|c|c|c|c|}
\hline Isolate & $\begin{array}{l}\text { Ciprofloxacin } \\
(\mathrm{mg} / \mathrm{ml})\end{array}$ & $\begin{array}{l}\text { Nalidixic acid } \\
(\mathrm{mg} / \mathrm{ml})\end{array}$ & & \\
\hline & ${ }_{-} \mathrm{P} \beta \mathrm{NA}$ & $+\mathrm{P} \beta \mathrm{NA}$ & ${ }_{-} \mathrm{P} \beta \mathrm{NA}$ & $+\mathrm{P} \beta \mathrm{NA}$ \\
\hline En $1^{*}$ & 73.33 & $<1.1457$ & $>146.66$ & $<1.1457$ \\
\hline $\operatorname{En} 2^{*}$ & 146.66 & $<1.1457$ & $>146.66$ & $<1.1457$ \\
\hline En3 & 18.33 & $<1.1457$ & $>146.66$ & $<1.1457$ \\
\hline En4 & $>146.66$ & $>146.66$ & $>146.66$ & $>146.66$ \\
\hline En5 & $>146.66$ & $>146.66$ & $>146.66$ & $>146.66$ \\
\hline En.6 & $>146.66$ & $>146.66$ & $>146.66$ & $>146.66$ \\
\hline En7 & $>146.66$ & $>146.66$ & $>146.66$ & $>146.66$ \\
\hline $\operatorname{En} 8^{*}$ & $<1.1457$ & $<1.1457$ & $<1.1457$ & $<1.1457$ \\
\hline P1 & 36.665 & 9.1663 & $>146.66$ & 9.1663 \\
\hline P2 & 73.33 & 9.1663 & $>146.66$ & $>146.66$ \\
\hline $\mathrm{P}^{*}$ & $>146.66$ & 73.33 & $>146.66$ & $>146.66$ \\
\hline P4 & 73.33 & 73.33 & $>146.66$ & $>146.66$ \\
\hline P5 & 36.665 & $<1.1457$ & 73.33 & $<1.1457$ \\
\hline $\mathrm{P}^{*}$ & $>146.66$ & 62.5 & $>146.66$ & $>146.66$ \\
\hline $\mathrm{P}^{*}$ & $>146.66$ & 73.33 & $>146.66$ & $>146.66$ \\
\hline
\end{tabular}

Table 4: MIC changes of ciprofloxacin and nalidixic acid before and after addition of PA $\beta \mathrm{N}$ for 8 Enterobacter, 8 Proteus.

* isolates which selected for PCR screening

\section{Discussion}

The occurrence of antibiotic-resistant bacteria of all genera has been on the rise. Efflux pumps are transport proteins involved in the extrusion of toxic substrates (including virtually all classes of clinically relevant antibiotics) from within cells into the external environment. The emergence and spread of MDR Enterobacteriaceae that cause human infections is increasing worldwide. The most common problematic pathogens in this family are: Klebsiella pneumoniae, Escherichia coli and Enterobacter spp. They are identified mostly in hospital settings but also as a source of community-acquired infections [1]. Urinary tract infections (UTI) are among the most common bacterial infections in various parts of the world with high medical costs. In this study the most common site of isolation was the urine $112(51.1 \%)$ [17].

In this study, the MICs of ciprofloxacin antibiotic and nalidixic acid antibiotics before and after addition of efflux pump inhibitor $\mathrm{Pa} \beta \mathrm{N}$ were measured in 219 strains with fixed concentration of $\mathrm{P} \beta \mathrm{NA}$ $(20 \mathrm{ug} / \mathrm{ml})$. Changes were detected in only 28 isolates. Helaly et al. [18] found that by increasing the concentration of $P A \beta N$, there is progressive reduction in MIC of ciprofloxacin and levofloxacin which is the same for concentration 25 and $50 \mu \mathrm{g} / \mathrm{ml}$ (8-and 16- fold for ciprofloxacin and levofloxacin, respectively), while at concentration of $100 \mu \mathrm{g} / \mathrm{ml}$ a more reduction in the MIC is noticed reaching 16 -fold for ciprofloxacin and 32-fold for levofloxacin (64-fold for E30). While

\begin{tabular}{|c|c|c|c|c|c|c|c|c|c|}
\hline Isolate & gyrA & parC & qnrA & qnrB & qnrS & $\operatorname{Aac}\left(6^{\prime}\right)-\mathrm{Ib}$ & qepA & oqxA & oqxB \\
\hline K26 & + & + & - & - & - & + & - & + & - \\
\hline K50 & + & + & + & - & + & + & + & + & + \\
\hline K17 & + & + & - & + & + & + & - & + & - \\
\hline En1 & + & + & - & + & + & + & - & + & - \\
\hline En2 & + & + & - & - & + & + & - & + & - \\
\hline P3 & + & + & - & - & - & + & - & + & - \\
\hline K47 & + & + & - & - & - & - & - & + & + \\
\hline K33 & + & + & - & - & + & + & - & + & + \\
\hline K62 & + & + & - & - & - & + & - & + & + \\
\hline K71 & + & + & - & - & + & + & - & + & + \\
\hline K3 & + & + & - & - & + & + & - & + & + \\
\hline E50 & - & + & + & - & - & + & - & - & - \\
\hline E11 & + & + & - & - & - & + & - & + & - \\
\hline E26 & + & + & - & - & - & - & - & - & - \\
\hline E78 & + & + & - & - & - & - & - & - & - \\
\hline E82 & + & + & - & - & - & - & - & - & - \\
\hline E59 & + & + & - & - & - & + & - & - & - \\
\hline E86 & + & + & - & - & - & + & - & - & - \\
\hline E20 & + & + & - & - & - & + & - & - & - \\
\hline E77 & + & + & - & - & - & + & - & + & - \\
\hline P6 & - & + & - & - & - & - & - & - & - \\
\hline P7 & - & + & - & + & - & + & - & - & - \\
\hline E3 & + & + & - & - & - & + & - & - & - \\
\hline K19 & + & + & - & + & - & + & - & + & + \\
\hline E96 & + & + & - & - & - & + & - & - & - \\
\hline En8 & - & - & - & - & - & - & - & - & - \\
\hline
\end{tabular}

Table 5: PCR screening results for Plasmid-mediated quinolone resistance genes and efflux pump genes. 
Citation: Khalil M, Elsherif R, Ghaith D, Ismail DK, Mohamed S, et al. (2017) Quinolone Resistance Detection by PCR-RFLP and Multiplex-PCR among Extended- Spectrum $\beta$ - Lactamase Producing Enterobacteriaceae. Int J Clin Med Microbiol 2: 119. doi: https://doi.org/10.15344/2456-4028/2017/119

Page 8 of 9

Lunn et al. [19] reported that when the MICs of ciprofloxacin were measured in the presence of PA $\beta \mathrm{N}$, ten of thenalidixic acid resistant isolates showed a 1.3- to 2-fold decrease, whereas no change was detected in any of the other seven isolates. In all but two isolates (MIC of $0.094 \mu \mathrm{g} / \mathrm{ml}$ ), susceptibilities to ciprofloxacin remained decreased in the presence of PABN. Glatz [20] observed that at least four-fold reduction in ciprofloxacin MICs was found in the presence of PA $\beta \mathrm{N}$ in $79 \%$ of representative isolates; at least eight fold reductions in ciprofloxacin MICs in the presence of PA $\beta \mathrm{N}(\mathrm{PA} \beta \mathrm{N}+)$ was detected in $37 \%$ of representative isolates. In another study conducted by Lavigne et al. [21] on five patients presented imipenem susceptible E. aerogenes strains, then intermediate or resistant isolates. They observed that the $\mathrm{PA} \beta \mathrm{N}$ addition reduced the MICs for Ofloxacin in all strains. Another study carried out by Yedekci et al. [13] noted changes in nalidixic acid and ciprofloxacin MIC values in the presence of fixed concentration of PA $\beta \mathrm{N}(20 \mathrm{pLg} / \mathrm{ml})$.

All the 33 strains were subjected to PCR-RFLP with the same PCR primers and restriction enzymes. PCR amplification of gyrA and parC was successful for all 33 clinical strains including the positive controls which generated products with the expected amplicon sizes of 344 and $168 \mathrm{bp}$. Our PCR-RFLP method is simple because the PCR primers and restriction enzymes are identical and the method is compatible with all 6 Enterobacteriaceae species. Therefore, the level of quinolones resistance for all 6 Enterobacteriaceae species may be determined without previous species identification from clinical specimens. The PCR-RFLP method provided results within $5 \mathrm{~h}$. Since plasmid-mediated quinolone resistance (PMQR) was first described in 1998, four types of PMQR determinants have been identified: $q n r$ $a a c\left(6^{\prime}\right)-I b-c r, q e p A$, and $o q x A B$ [22]. The qnr genes are transferable genes that confer low-level quinolone resistance by protection of topoisomerase, qnrA had an additive effect of a 10-fold increase in the minimum inhibitory concentration (MIC) whatever the number of topoisomerase mutations, and $q n r S$ was additive to qnrA with a further 2- to 10-fold increase in the MIC [23].

In Egypt a study carried out by Hassan et al. [24] who found that out of 30 ESBL producers E. coli isolates, 8 (26.6\%) were positive for $q n r$ genes, and the qnrA1-, qnrB1 and qnrS1-type genes were detected alone or in combination in $5(16.6 \%), 7(23.3 \%)$ and $5(16.6 \%)$ isolates, respectively. Recently, the association of aac(6)-Ib-cr with genes encoding the beta-lactamase CTX-M-15 or other ESBLs has been reported [25]. The qepA gene, together with the qnr family and $a a c\left(6^{\prime}\right)-I b c r$, is the third recently detected plasmid-borne determinant of resistance to the fluoroquinolones. These genes confer only lowlevel resistance, but their presence could potentially facilitate evolution of the bacterial host toward higher levels of resistance by mutational alterations in the target type II topoisomerases [26 ]. qepA gene was detected in only one Klebsiella isolate in this study which was highly resistant to both antibiotics before and after the addition of the efflux pump inhibitor $\mathrm{Pa} \beta \mathrm{N}$. oq $x A / O q x B$ is highly prevalent in diverse MDR K. pneumoniae of human origin. This efflux pump may be an important factor contributing to the MDR profile of $K$. pneumoniae, and to its versatility as a zoonotic and nosocomial colonizer [27] Among the $83 \mathrm{~K}$. pneumoniae strains, Taherpour and Hashemi [28]. found that $48(57.5 \%)$ were ESBL positive. The prevalence of both oqxA and oqxB detected in K. pneumonia was high: 50 (60.2\%) and $50(60.2 \%)$, respectively. In this study, fosfomycin and tigecycline were more active than other antibiotics Isolates positive for both oqxA and oq $x B$ were regarded as oqxAB positive as the oqxA $B$ is encoded by oqxA and oqxB in the same operon [22].

\section{Conclusion}

The presence of co-resistance among different classes of antibiotic families was significant among the ESBL-producing Enterobacteriaceae. The PaßN was an effective phenotypic screening method for quinolones resistance. The data obtained suggests the wide occurrence of PMQR genes in clinical ESBL -producing ciprofloxacin resistant Enterobacteriacae isolates. Also the present study provides sufficient data suggesting that PCR-RFLP methodology is a simple and rapid method (it can be performed within 5 hours) for the detection of ciprofloxacin-resistant strains useful for clinical diagnosis and epidemiological studies. Routine surveillance of microbial population to determine the extent of antibiotic resistance should be conducted to provide suitable treatment guidelines.

\section{Competing Interests}

The author declares that the has no competing interests.

\section{Author Contributions}

All authors contributed to, designed, and coordinated the study.

Study concept and design: MK, DI, and SM. Microbiological analysis of the samples: RE, DI, SE and SJ.

Acquisition of data: RE, DI, and SE. Analysis and interpretation of data: SJ, RE, DJ, SE, and SM.

Drafting of the manuscript: GK, RE, DI, and SE. Critical revision of the manuscript for important intellectual content, RE, DI, SE, and GK. Study supervision: MK, RE, DI, SA, SJ, and SE. All authors read and approved the final manuscript.

\section{Acknowledgments}

The authors acknowledge the Faculty of Medicine, Cairo University for technical and general support.

\section{References}

1. Falagas ME, Karageorgopoulos DE, Nordmann P (2011) Therapeutic options for infections with Enterobacteriaceae producing carbapenem-hydrolyzing enzymes. Future Microbiol 6: 653-666.

2. Poole $\mathrm{K}$ (2003) Overcoming multidrug resistance in gram-negative bacteria. Curr Opin Investig Drugs 4: 128-139.

3. Ball P (2000) Quinolone generations: natural history or natural selection? J Antimicrob Chemother 46 Suppl T1: 17-24.

4. Coque TM, Baquero F, Canton R (2008) Increasing prevalence of ESBLproducing Enterobacteriaceae in Europe. Euro Surveill 13

5. Strahilevitz J, Jacoby GA, Hooper DC, Robicsek A (2009) Plasmid-mediated quinolone resistance: a multifaceted threat. Clin Microbiol Rev 22: 664-689.

6. Robicsek A, Jacoby GA, Hooper DC (2006) The worldwide emergence of plasmid-mediated quinolone resistance. Lancet Infect Dis 6: 629-640.

7. Alonso R, Mateo E, Girbau C, Churruca E, Martinez I, et al. (2004) PCRRestriction Fragment Length Polymorphism Assay for Detection of gyrA Mutations Associated with Fluoroquinolone Resistance in Campylobacter coli. Antimicrobial Agents and Chemotherapy 48: 4886-4888.

8. Poole K (2005) Efflux-mediated antimicrobial resistance. J Antimicrob Chemother 56: 20-51.

9. Ruiz J (2003) Mechanisms of resistance to quinolones: target alterations, decreased accumulation and DNA gyrase protection. J Antimicrob Chemother 51: 1109-1117.

10. Fadli M, Chevalier J, Saad A, Mezrioui NE, Hassani L, et al. (2011) Essentia oils from Moroccan plants as potential chemosensitisers restoring antibiotic activity in resistant Gram-negative bacteria. Int J Antimicrob Agents 38 : 325-330. 
Citation: Khalil M, Elsherif R, Ghaith D, Ismail DK, Mohamed S, et al. (2017) Quinolone Resistance Detection by PCR-RFLP and Multiplex-PCR among Extended- Spectrum $\beta$ - Lactamase Producing Enterobacteriaceae. Int J Clin Med Microbiol 2: 119. doi: https://doi.org/10.15344/2456-4028/2017/119

Page 9 of 9

11. Lamers RP, Cavallari JF, Burrows LL (2013) The efflux inhibitor phenylalaninearginine beta-naphthylamide (PABN) permeabilizes the outer membrane of gram-negative bacteria. PLoS One 8: 3.

12. Clinical and Laboratory Standards Institute (2010) Performance standards for antimicrobial susceptibility testing. M100-S20. CLSI, Wayne, PA.

13. Yedekci S, Erac B, Limoncu MH (2012) Detection Of The Efflux PumpMediated Quinolone Resistance In ESBL Positive Escherichia Coli And Klebsiella Pneumoniae Isolates by Phe-Arg-?eta Naphthylamide. Turk J Pharm Sci 9: 67-74.

14. Kim HB, Park CH, Kim CJ, Kim, EC, Jacoby, GA, et al. (2009a) Prevalence of Plasmid-Mediated Quinolone Resistance Determinants over a 9-Year Period. Antimicrobial Agents Chemother 53: 639-645.

15. Wang Y, Huang WM, Taylor DE (1993) Cloning and nucleotide sequence of the Campylobacter jejuni gyrA gene and characterization of quinolone resistance mutations.Antimicrob. Agents Chemother 37: 457-463.

16. Kim HB, Wang M, Park CH, Kim EC, Jacoby GA, et al. (2009b) oqxAB encoding a multidrug efflux pump in human clinical isolates of Enterobacteriaceae. Antimicrob Agents Chemother 53: 3582-3584.

17. Mohajeri P, Darfarin G, Farahani A (2014) Genotyping ofESBL-producing Uropathogenic Escherichia coli in West of Iran. International Journal of Microbiology 2014: 276941.

18. Helaly GF, Abou-Shleib H, Fanaki NH, Abdel-Kader O, Ali GH (2010) Potentia Co-prevalence of Plasmid-Mediated Quinolone Resistance Determinant qepA and $16 \mathrm{~S}$ rRNA Methylase rmtB among E.coli Clinical Isolates from Alexandria- Egypt. J Egy Pub Health Assoc 85: 247-272.

19. Lunn, AD, Fàbrega, A, Sánchez-Céspedes J, Vila J (2010) Prevalence of mechanisms decreasing quinolone-susceptibility among Salmonella spp. Clinical isolates. Int Microb 13: 15-20.

20. Glatz KMD (2012) Antimicrobial susceptibility and molecular epidemiology of drug resistant bacterial pathogens of healthcare-associated infections, Doctoral thesis.

21. Lavigne JP, Sotto $A$, Nicolas-Chanoine $M H$, Bouziges $N$, et al. (2011) Membrane permeability, a pivotal function involved in antibiotic resistance and virulence in Enterobacter aerogenes clinical isolates. Clin Microbio Infect 18: 539-545.

22. Park CH, Robicsek A, Jacoby GA, Sahm D, Hooper DC (2006) Prevalence in the United States of aac $\left(6^{\prime}\right)$-Ib-cr encoding a ciprofloxacin-modifying enzyme. Antimicrob Agents Chemother 50: 3953-3955.

23. Lascols C, Robert J, Cattoir V, Bébéar C, Cavallo, JD, et al. (2007) Type I topoisomerase mutations in clinical isolates of Enterobacter cloacae and other enterobacterial species harbouring the qnrA gene. Int J Antimicrob Agents 29: 402-9.

24. Hassan WM, Hashim A, Domany R (2012) Plasmid mediated quinolone resistance determinants qnr, aac(6')-Ib-cr, and qep in ESBL-producing Escherichia coli clinical isolates from Egypt. Indian J Med Microbiol 30: 442447.

25. Paiva MC, Nascimento AMA, Camargo ILBC, Lima-Bittencourt CI, Nard RMD (2012) The first report of the qnrB19, qnrS1 and aac(6')-Ib-cr genes in urinary isolates of ciprofloxacin-resistant Escherichia coli in Brazil. Mem Inst Oswaldo Cruz 107: 687-689.

26. Perichon B, Courvalin P, Galimand M (2007) Transferable resistance to aminoglycosides by methylation of G1405 in 16S rRNA and to hydrophilic fluoroquinolones by QepA-mediated efflux in Escherichia coli. Antimicrob Agents Chemother 51: 2464-2469.

27. Perez F, Rudin S, Marshall S, Chen L, Coakley P, et al. (2013) OqxAB, a Quinolone and Olaquindox Efflux Pump, Is Widely Distributed among Multidrug-Resistant Klebsiella pneumoniae Isolates of Human Origin. Antimicrob Agents Chemother 57: 4602-4603.

28. Taherpour A, Hashemi A (2013) Detection of oqxAB efflux pumps, OmpK35 and OmpK36 porins in extended-spectrum-ß-lactamase-producing Klebsiella pneumoniae isolates from Iran. Hippokratia 17: 355-358. 